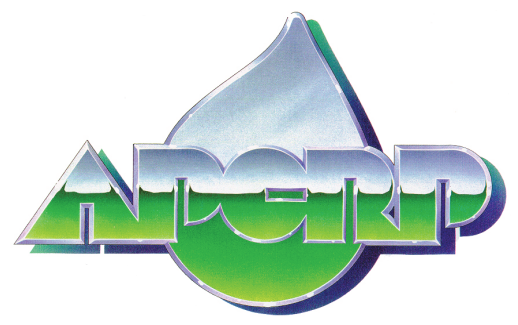

ERDC/TN APCRP-MI-8

January 2014

\title{
Establishing Research and Management Priorities for Monoecious Hydrilla
}

by M. D. Netherland and Mike Greer

PURPOSE: The purpose of this technical note is to provide:

a) A synthesis of key points from presentations and discussions following a September 2012 Symposium on the Biology and Management of Monoecious Hydrilla,

b) Background information on monoecious hydrilla and a description of why the spread of this biotype into the northern tier states should concern policymakers and resource managers, and

c) A list of research and management priorities for monoecious hydrilla that will serve to address significant information gaps and encourage innovative approaches to this problem.

As the monoecious biotype of hydrilla encroaches on unique water resources of northern glacial lakes and streams, we are embarking on a large-scale regional experiment that will test policies and maxims such as: 1) Prevention; 2) Early Detection/Rapid Response; 3) Eradication vs. Containment; 4) Interstate Cooperation; and 5) the Role of Research and Demonstration in Addressing Resource Management Issues. Will monoecious hydrilla be a serious invader in this region or will the level of threat not live up to current predictions? The timely answer to this question is of paramount importance to resource managers, policy makers, and stakeholders throughout the North.

INTRODUCTION: The submersed plant hydrilla (Hydrilla verticillata L.f. Royle) has been recognized as a serious aquatic invasive species in the United States for several decades; it has even been called the "perfect aquatic weed" (Langeland 1996). The recent discovery of hydrilla in high-profile areas such as the inlet of Lake Cayuga, New York and in several miles of the Erie Canal near Tonawanda, New York has stimulated numerous questions regarding the biology, invasion ecology, and management of hydrilla in northern tier lakes and waterways. Given the likelihood for continued spread of hydrilla into northern waters, a September 2012 Symposium was organized by the US Army Engineer Research and Development Center's Aquatic Plant Control Research Program to identify research and management needs for the monoecious biotype of hydrilla. Researchers and managers from federal and state agencies, universities, non-profit organizations, and private industry gathered in Syracuse, New York to focus on monoecious hydrilla. This technical note summarizes key points and discussions that resulted from this Symposium.

SYNTHESIS OF KEY POINTS: Why focus on a specific biotype of hydrilla? As hydrilla has continued to spread to new states and waterways, it is evident that the monoecious biotype has become particularly mobile. Between the years 2000 and 2011, the dioecious biotype was only documented in three new states, while the monoecious biotype was documented in 11 new northern states as well as in four additional southern states (Alabama, South Carolina, Georgia, and Tennessee) that were previously recognized as supporting only dioecious hydrilla. It is expected that overlap of biotypes 
within water bodies is likely to become more prevalent in Southeastern waters. ${ }^{1}$ While the monoecious biotype of hydrilla has continued to spread into new states, there has not been a concomitant increase in new information or expanded research for this biotype. In fact, the vast majority of published literature and management experience relates to the dioecious biotype of hydrilla. A recent request to the University of Florida Center for Aquatic and Invasive Plants (UF CAIP) Aquatic Plant Information Office for publications and abstracts on monoecious hydrilla indicated that of 5011 records including the term "hydrilla," only 197 records included the terms "monoecious or biotype." The Northeast Aquatic Nuisance Species (NEANS) panel recently commissioned a literature review on monoecious hydrilla by Dr. Rob Richardson from North Carolina State University; this review can be found at www.northeastans.org. This review provides a thorough description of articles on monoecious hydrilla; therefore, the current technical note will not focus heavily on literature. As noted in many of these articles and in the Symposium presentations, distinct differences in the biology of the two hydrilla biotypes are important both in terms of invasion ecology and management implications. It is rare for biotypes of the same plant species to demonstrate such fundamental differences in reproductive biology, propagule formation and quiescence, perennial versus annual growth habit, and general morphological characteristics. While such biotype differences have been noted for some grass species (Paspalum, Poa, and Paspalum notatum) in terrestrial systems, such distinct biotype differences in aquatic plants are not well-known. The cumulative differences between the hydrilla biotypes led several Symposium speakers to note that it is almost as if "we are dealing with two different species."

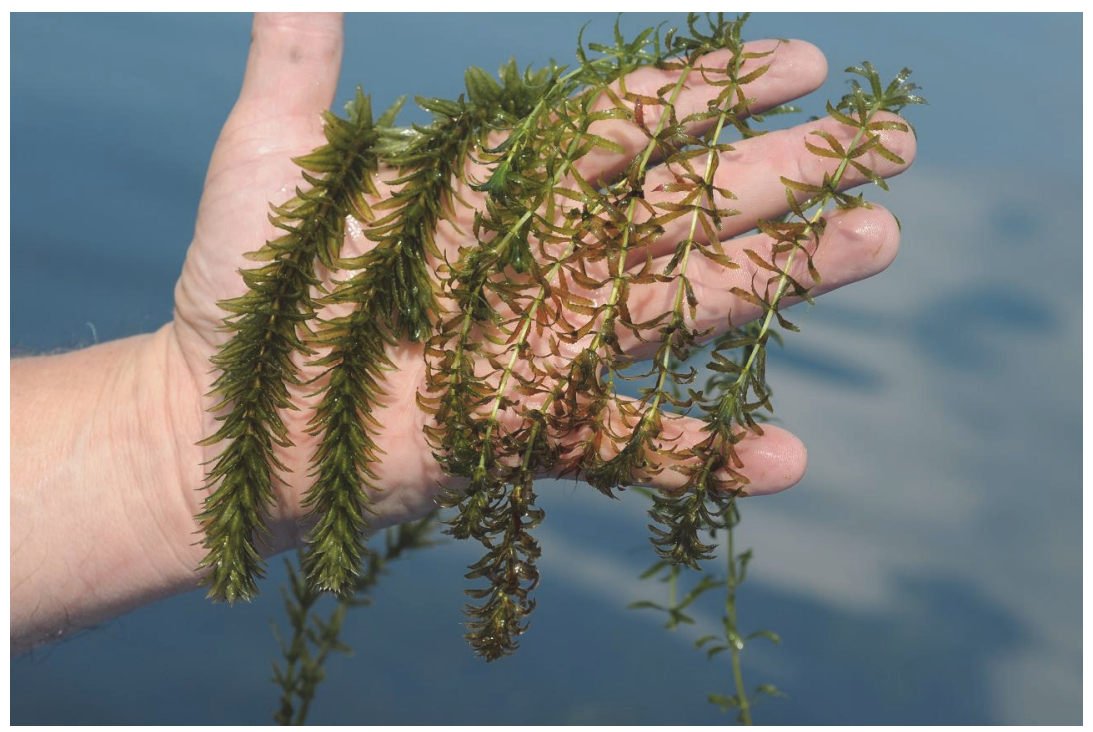

Figure 1. Dioecious (left) and Monoecious (right) strains of hydrilla collected from Guntersville Reservoir, Alabama.

\footnotetext{
${ }^{1}$ The recent expansion of hydrilla to 20,000 acres on Lake Guntersville in North Alabama provides an interesting twist. This reservoir on the Tennessee River now supports large populations of both the monoecious and dioecious strains of hydrilla. As management efforts have been fairly minimal over the past decade, this reservoir may provide some clues as to how monoecious hydrilla competes with what is often considered a superior competitor. Monoecious hydrilla has been described as the "weak cousin of the dioecious biotype"; nonetheless, the physical appearance of individual shoots may be a very poor indicator of the invasive traits of this plant. The introduction and spread of the monoecious biotype of hydrilla in this system represents a new invasion.
} 
Given the recent expansion of the monoecious biotype in northern tier states and the lack of some key information on biology, ecology, and management for this biotype, the Symposium objectives focused on monoecious hydrilla and its potential impact in northern states. Recognizing the abundance of knowledge gaps, talks and discussion focused on biology, invasion ecology, and management of the monoecious biotype in northern tier waters. It is somewhat paradoxical to note that while several eradication programs are ongoing for monoecious hydrilla invasions around the country, these eradication programs in some ways actually contribute to the lack of information regarding the biology and ecology of monoecious hydrilla in northern tier waters. This is not intended to suggest that managers should allow monoecious hydrilla to spread in order to learn more about the plant; however, it does point out that in spite of limited research and actual field observations in northern tier lakes, managers are generally committed to eradication programs of this biotype.

What is at risk in glacial lakes of the Northern tier states? As hydrilla moves into the northern tier states, questions often arise regarding why there is such a special concern about this region. For the purposes of this discussion, the northern tier is defined as those states that have abundant natural glacial lakes that support varying densities of native submersed vegetation. Essentially, the border states stretching from Maine to Minnesota fit this definition. Monoecious hydrilla is considered highly invasive in large reservoirs of the Mid-Atlantic states; however, widespread use of grass carp and a general lack of submersed native vegetation in these systems have not provided much information regarding how aggressive or competitive hydrilla is likely to be in the northern tier lakes. It is interesting to note that monoecious hydrilla has thrived in some of these high-energy/high-water fluctuation reservoirs as well as in numerous rivers. This has led to speculation that monoecious hydrilla might be particularly well-suited to drawdowns or fluctuations in water levels, high spring flows, and early spring turbidity (i.e. disturbance) as the dormant tuber bank is largely responsible for recovery on a year-to-year basis. Reports of the establishment of monoecious hydrilla on large stretches of the Ohio River (Pennsylvania, West Virginia, Ohio, and Kentucky) are of particular concern, as these infestations may be a source of new and continuing introductions into northern tier lakes (Figure 2). As reflected by the recent finds of hydrilla in high-profile water bodies such as Cayuga Lake Inlet and the Erie Canal, disjunct introductions (i.e. lakes far away from a current source of hydrilla) will remain a significant challenge for resource managers and preparation of special response plans for high-profile/high-use water bodies is warranted. While this document does not focus on the Cayuga Lake Inlet hydrilla infestation and management response, this topic was thoroughly covered during a special session of the Symposium. Information on the status of the Lake Cayuga hydrilla eradication project can be accessed via the NEANS website mentioned above or at http://ccetompkins.org/environment/

invasive-species/hydrilla.

The northern tier lakes in the United States represent a unique resource from a worldwide perspective. This large regional concentration of thousands of natural lakes relies on native vegetation communities to support the ecological health of the water body. This in turn supports a thriving real estate and recreation industry. The northern tier lakes do not have an analogue anywhere within or outside of the United States. The addition of hydrilla to these systems carries a high risk of rapid inter-lake spread with unknown consequences. These early infestations of monoecious hydrilla are analogous to the introduction of Eurasian watermilfoil (Myriophyllum spicatum) into these same northern tier waters in the 1950s, 60s, and 70s. The experience with the historical spread and management of Eurasian watermilfoil has likely impacted current policies that emphasize eradication of nascent monoecious 
hydrilla populations in several northern states (e.g. Indiana, Maine, Massachusetts, New York, Ohio, Washington, and Wisconsin). Given the recent focus on prevention of spread as the key tool in invasive species management, these eradication programs for isolated hydrilla populations are widely supported. ${ }^{1}$ Unfortunately, without a better understanding of the source of these hydrilla introductions, it is likely that multiple introductions into additional key water bodies would severely strain this strategy from both an economic and environmental standpoint.

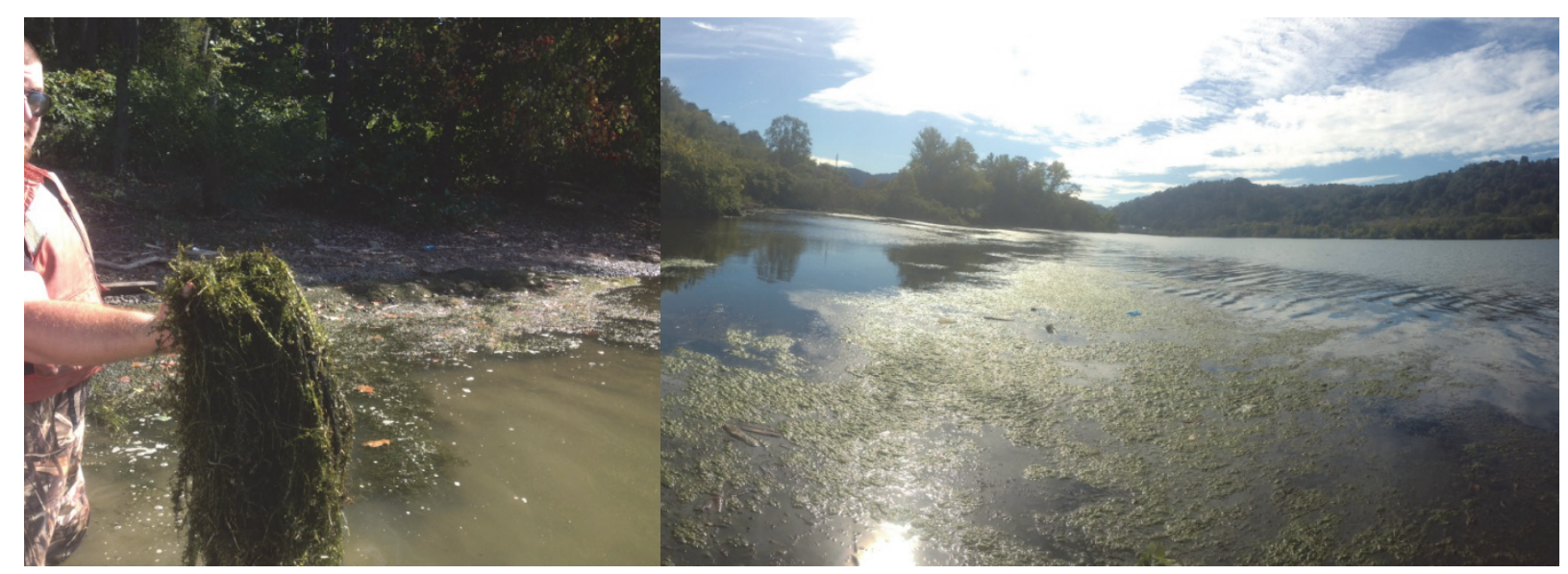

Figure 2. Hydrilla growing along the shoreline of the Ohio River near West Virginia. Pictures courtesy of Ryan Argo, Ohio River Valley Water Sanitation Commission.

Prior and current research and management efforts. The discovery of a different biotype of hydrilla in the Potomac River region in the mid 1980s led to several initial research efforts to characterize monoecious hydrilla. The majority of this research focused on differences in vegetative propagule production between the two biotypes. Key differences between the hydrilla biotypes include the following information gleaned from the literature as well as observations from resource managers: 1) tuber and turion production differ between monoecious and dioecious biotype; monoecious tubers are initiated in the summer and persist well into the fall (Spencer and Anderson 1986, Steward and Van 1987, Van 1989, Van and Steward 1990, Steward 1991, Sutton et al. 1992, Spencer et al. 1994, Spencer and Ksander 2000, Owens et al. 2012); 2) in more temperate areas, sprouting of monoecious hydrilla tubers occurs in the spring/early summer and is regulated by water temperature (Netherland 1997, Spencer and Ksander 2001); 3) once tubers or turions sprout, the monoecious hydrilla first grows laterally along the bottom sediments and then starts to grow to the surface; 4) the plant can produce viable seed (Conant et al. 1984, Lal and Gopal 1993; 5) in more temperate regions monoecious hydrilla biomass dies back completely in the fall and relies on tubers for regeneration the following growing season (Harlan et al. 1984); and 6) under eradication programs, a large decline in monoecious hydrilla tuber numbers is observed the first year; however, viable tubers can persist for 5 to 10 years.

\footnotetext{
${ }^{1}$ While many recent high-profile aquatic invasive species (AIS) issues involve invertebrates and fish (e.g. zebra mussels, Asian carp, gobies), other than prevention efforts, resource managers are generally not actively engaged in "eradicating or managing" new invasions in natural systems. In contrast, aquatic plant management has a long history, an industry presence, and each state has developed programs and policies that address invasive plants such as Eurasian watermilfoil, variable watermilfoil, or curlyleaf pondweed. In the case of plant management, there is often a strong stakeholder demand from lake residents, boaters, or fishing interests that invasive plants be managed once they become established. Given the current public education efforts regarding the potential threat hydrilla poses to this region, it is likely that stakeholders will put significant pressure on resource managers to address both new and established infestations of this plant.
} 
In addition to the information on monoecious hydrilla biology, research efforts to develop genetic tests to distinguish between the biotypes were successful and variations of these early tests are in use today (Ryan et al. 1991; Madeira et al. 2004; Rybicki et al. 2013). This testing has confirmed the recent expansion of the monoecious biotype and it will be particularly valuable in determining competitive interactions between the hydrilla biotypes in large southern reservoirs where overlap has been documented. In addition to research efforts, managers have been implementing eradication programs for monoecious hydrilla in numerous states. The key feature of these efforts has been the requirement to combine multiple years of whole-system management (or intense treatment within a given site) with extensive monitoring programs. Table 1 is a short synopsis of several eradication programs.

\begin{tabular}{|l|l|l|l||}
\hline \multicolumn{2}{||l|}{ Table 1. An overview of various monocious eradication projects in northern tier lakes. } \\
\hline \hline Lake and State & $\begin{array}{l}\text { Lake Size, } \\
\text { acres }\end{array}$ & Management & Status \\
\hline Pipe and Lucerne, WA & 67 & $\begin{array}{l}\text { Whole-lake fluridone 1995-2000 } \\
\text { Hand pulling 2001-02 } \\
\text { Whole-lake fluridone 2003-07 }\end{array}$ & $\begin{array}{l}\text { Declared } \\
\text { eradication } 2010\end{array}$ \\
\hline Long Pond, MA & 49 & $\begin{array}{l}\text { Whole-lake or basin-wide fluridone } \\
\text { 2002-2012 }\end{array}$ & $\begin{array}{l}\text { Ongoing - >97\% } \\
\text { tuber attrition }\end{array}$ \\
\hline Pickerel Pond, ME & 49 & Whole-lake fluridone 2003-11 & $\begin{array}{l}\text { No new finds in } \\
\text { 2013 }\end{array}$ \\
\hline Lake Manitou, IN & 809 & Whole-lake fluridone 2007-12 & $\begin{array}{l}\text { Ongoing -99\% } \\
\text { tuber attrition }\end{array}$ \\
\hline Clear Lake, CA & 43,000 & $\begin{array}{l}\text { Spot treatments with fluridone 1994 - } \\
\text { 2012 (no treatment in 2006) }\end{array}$ & Ongoing \\
\hline Lake Cayuga Inlet, NY & $\begin{array}{l}166 \\
(\text { Lake Cayuga= } \\
43,000)\end{array}$ & $\begin{array}{l}\text { Inlet treated with endothall in fall 2011 } \\
\text { Inlet treated with endothall followed by } \\
\text { fluridone in summer 2012 }\end{array}$ & Ongoing \\
\hline
\end{tabular}

While progress has been made regarding understanding of monoecious hydrilla, there are many key knowledge gaps that prevent both researchers and managers from developing a better understanding of the potential threat this plant poses in the region.

Given the costs, scale of management, and long-term commitments required by hydrilla eradication programs ( 5 to $8+$ years), a renewed effort to focus on basic questions regarding plant biology and invasion ecology would be valuable to policymakers and managers as monoecious hydrilla continues to spread into this unique region of the country.

Monoecious hydrilla growth in the northern tier states. Numerous efforts have been made to predict the potential for the northern expansion of hydrilla in North America. As noted by several Symposium presenters, hydrilla can be found in Asia at latitudes greater than 50 degrees (i.e. all areas of the continental United States are susceptible). Given the abundance of native submersed aquatic vegetation (SAV) growth in northern tier lakes, models suggesting that monoecious hydrilla would not be invasive or competitive in this region rely on a hypothesis of thermal constraints to growth. The monoecious strain of hydrilla found in the United States originated from Korea ( 38 degrees latitude). However, aside from minimal occurrence information in Korea (www.gbif.org), there is no published information (in English) regarding invasive traits of this particular biotype of hydrilla in Korea or in other regions. A recent thesis publication (Benoit 2011) indicates that both the dioecious and monoecious strains of hydrilla introduced into the United States are polyploids. This may be the key 
factor in explaining their aggressive growth in the United States when compared to other strains of hydrilla on a worldwide basis. While there are numerous hypotheses regarding the invasive potential of monoecious hydrilla, information regarding the environmental constraints limiting the establishment and spread of monoecious hydrilla as it moves northward is imperfect. Attempts have been made to determine the competitive nature of different strains of hydrilla (Steward 1991, Hofstra et al. 1999, Spencer and Ksander 2001, Chadwell and Engelhardt 2008, Hofstra et al. 2010). Additional research focusing on the northern tier water bodies would be valuable in determining the competitive abilities of monoecious hydrilla.

As noted above, the northern tier lakes can support abundant submersed plant growth and many of these species can grow rapidly from dormant vegetative propagules under increasing temperature and photoperiod regimes in the late spring and early summer. A key question relates to both the growth rate and competitive ability of monoecious hydrilla in this environment. While work on monoecious hydrilla conducted in Florida or California (or under laboratory conditions) can be suggestive of outcomes, limitations to this data remain. Likewise, while some basic information exists regarding competitive traits of dioecious hydrilla (e.g. low light and $\mathrm{CO}_{2}$ compensation points, ability to utilize a C-4-like photosynthesis system, rapid growth rates), many of these characteristics have not been documented for the monoecious strain. Efforts have been made to better understand the physiology and environmental constraints on monoecious hydrilla (Carter et al. 1987; McFarland and Barko 1987, 1999; Sutton et al. 1992; Maki and Galatowitsch 2008) and this type of work should serve as a good baseline for additional trials focusing on environmental factors that impact invasion biology and spread of the monoecious biotype. The potential long-term ability of the monoecious biotype to out-compete native and invasive SAV in northern tier lakes, expand into deeper water, or dominate in more turbid water systems is largely unknown. In the case of the dioecious biotype of hydrilla, it has invaded many areas that were devoid of submersed vegetation and covered large expanses of water bodies that were not previously colonized by SAV (Hoyer et al. 2008).

The reported success of monoecious hydrilla in colonizing extensive shoreline areas of the Ohio River has come as a surprise to many scientists who study hydrilla biology. The ability of this invasive plant to become established in the Ohio and several other rivers may suggest some environmental adaptations that have not been well characterized. Establishment in rivers is of particular concern due to the limited set of management tools available in these flowing systems and the potential for rivers to serve as a continuous source for spread of hydrilla to the potentially more vulnerable natural lakes. The current infestation of monoecious hydrilla in the Erie Canal near Buffalo ( $\sim 13$ miles of canal supports varying levels of hydrilla) represents a significant management challenge due to continuous flow. Yet this challenge must be addressed because the canal represents a key conduit for potential spread throughout important water bodies of New York State and potentially into Canada. While this population was confirmed in September 2012, it is unknown whether it represents a new infestation or one that has been present for a longer period of time. One can only speculate.

Management options for monoecious hydrilla. Discussion of management options during the Symposium suggested that the current toolbox is limited and unlikely to improve significantly in the near future without development of innovative R\&D and management strategies. While use of high stocking rates of non-selective sterile grass carp (Ctenopharyngodon idella) has successfully controlled hydrilla in many reservoirs in the Mid-Atlantic States, several policy and technical issues 
are associated with release of these fish in natural lakes of the northern tier states. The key obstacles are the likelihood of non-selective feeding (i.e. complete vegetation removal), the requirement for high stocking rates in the cooler northern lakes, and the difficulty of removing fish once they have been stocked. Likewise, discussions of classical biological control agents (e.g. insects that feed specifically on hydrilla) did not yield any promising near-term candidates for release. There was some discussion of the need to identify organisms specific to the strain of monoecious hydrilla in Korea. Cultural controls such as drawdowns and freezing sediments were discussed and these strategies may have some utility in sites where extended winter drawdowns are possible. Diverassisted dredging techniques and hand removal techniques were explored on the infestation in the Lake Cayuga inlet; initial results were not favorable. Issues associated with disposal of dredged material containing viable hydrilla tubers were also discussed. Several presentations on chemical control strategies using US Environmental Protection Agency (USEPA) registered herbicides were given. Based on the discussions, there was a general consensus that aquatic herbicides provide the most feasible current means for meeting hydrilla eradication/containment objectives in public waters.

Eradication versus containment. As the list of available management options proved to be limited, some of the Symposium discussion veered towards the policy of eradication versus containment. While eradication programs seek to remove hydrilla from a given system via attrition of the tuber bank (a process that can require multiple years of intense management), containment efforts would be more focused on preventing hydrilla from reaching a critical threshold that would allow offsite movement (e.g. boat trailers). If hydrilla infestations continue to increase across multiple lakes and state boundaries, the ability to implement and finance numerous eradication programs will likely differ between state agencies. Budgets and staff time will also be stretched significantly. Containment remains a more undefined policy, and to date it has not generally been recognized as a practical management tool in the field of aquatic plant management. Nonetheless, there was some recognition during the Symposium that eradication efforts may not always be possible or advised for various reasons. Therefore, development of containment policies would help managers identify long-term objectives and select the parameters that would define successful implementation of this strategy.

While several of the attendees had strong philosophical concerns with containment as a strategy (i.e. containment is basically giving up), it should be noted that significantly reducing viable hydrilla biomass may be the strongest prevention tool that can be brought to the fight against the spread of hydrilla. Work by Roley and Newman (2008) showed that the best predictor for a lake to be invaded by Eurasian watermilfoil is a nearby lake containing this plant. This principle would seem to be true for a wide variety of invasive submersed plants. Determining the need for aggressive management versus targeted management was a topic of discussion. The following scenarios provide a conceptual framework for addressing this issue:

1. For large riverine infestations like the Ohio River, which preclude any realistic form of largescale management, there should be discussion of establishing state or federal policies requiring that public access points must be actively managed to minimize risk of spread via boat trailers and other public usage. This would accompany other prevention/public education strategies.

2. Smaller riverine infestations with high risk of spread into non-infested waters, particularly of major economic and ecological value (Erie Canal, New York and Eno River, North Carolina are examples), should be prioritized for management at a very high level. These projects will 
challenge many standards of management....high flow, high cost, limited tools, and a challenging regulatory climate..... but a serious effort to significantly slow or prevent the spread of monoecious hydrilla in the north must have a strategy for these types of sites.

3. A standard program should be developed for smaller isolated pond infestations. This program should recommend two treatment options: 1) a higher stocking rate of grass carp (where selectivity is not an issue), or 2) one or two cycles of herbicide treatment to reduce tuber densities followed by low-rate grass carp stocking with the objective to achieve more selective outcomes with carp.

4. Small infestations within larger, public lakes (Cayuga, for example, even though the infestation is located in an inlet versus the lake proper) should be aggressively managed for eradication but transition to more of a containment/long-term management approach if they become too widespread. Some larger lakes (e.g., Waccamaw Lake in North Carolina) may lend themselves to larger-scale eradication efforts if the economic and ecological values preserved by such an approach can be well-communicated to policy/budget decision makers.

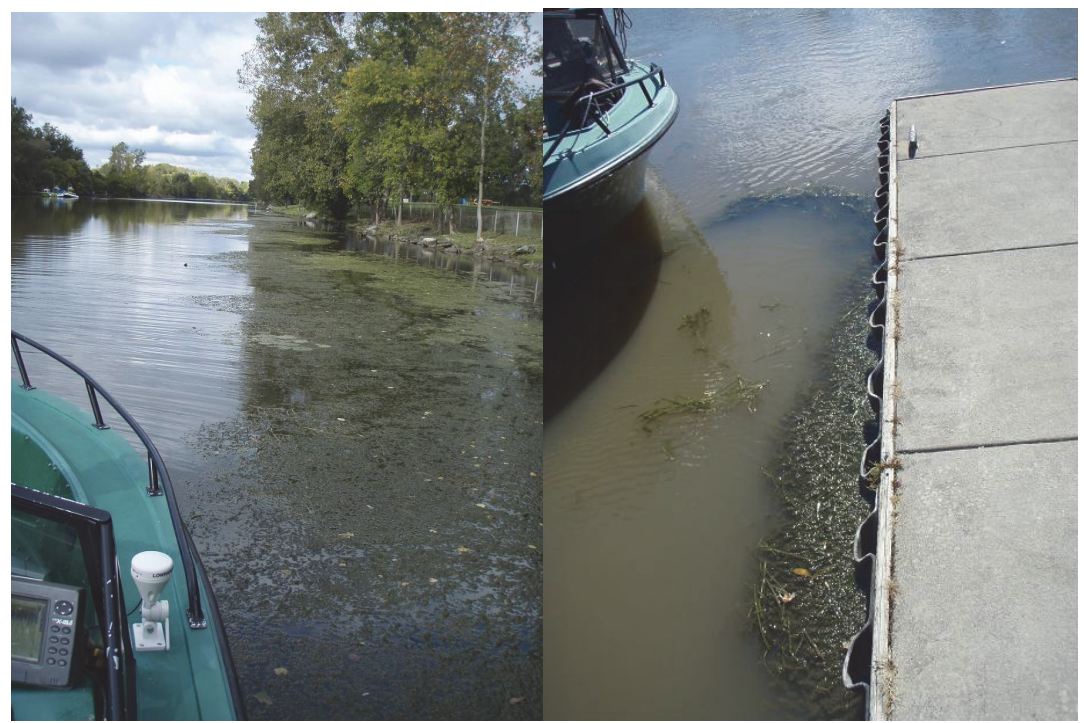

Figure 3. Hydrilla growing in the Erie Canal and along public access points.

Identifying research and management priorities. During the Symposium, research priorities were discussed in small groups. One of the objectives of breaking into smaller groups was to determine if common themes would be identified during these discussions. There were some interesting commonalities among the groups.

Current research activities. As noted above, the NEANS Panel funded a literature review on monoecious hydrilla and this should serve as a resource for researchers and managers interested in developing novel research projects to address this emerging problem. In 2010, the Aquatic Plant Management Society awarded a graduate student stipend to Dr. Rob Richardson at North Carolina State University (NCSU) to evaluate the phenology and competitive abilities of monoecious hydrilla. This work is nearing completion and should also provide some valuable insight. In 2012, the USEPA, through the Great Lakes Restoration Initiative (GLRI), funded a project evaluating the potential use of environmental DNA (eDNA) to improve the ability of managers to detect the presence of hydrilla and 
other AIS in aquatic systems. The USEPA also utilized GLRI funds to support a Nature Conservancy effort to develop models to predict the spread of hydrilla across New York, northwest Pennsylvania, and the eastern Ohio portion of the Great Lakes Basin. The US Army Corps of Engineers Buffalo District has provided GLRI funds to improve information on performance of the herbicides fluridone and endothall on monoecious hydrilla.

Identifying research and management priorities. In presenting the topics below, the objective is to stimulate novel targeted research and project management approaches to addressing monoecious hydrilla in northern tier waters. This list does not include all of the various ideas discussed as research and management priorities, but it does represent areas of strong consensus.

1. Determine where the hydrilla is coming from. All of the groups focused on the issue of determining the provenance of hydrilla introductions into the northern tier waters. Topics discussed included potential movement by 1) waterfowl via ingestion of seeds (as well as viability of seeds) or propagules, 2) aquatic plant trade, 3) rivers or other aquatic sources via boat traffic or trailers. The broad agreement on this topic likely reflects the consensus that prevention of spread is the most cost-effective way to address invasive species issues. Given the disjunct nature of hydrilla introductions, identifying the most important vectors versus speculating on various potential vectors for spread would be of great value to resource managers. During this discussion, it was also made clear that nearby infested sites represent the greatest threat for additional spread (Roley and Newman 2008). Some participants conveyed that more emphasis should be placed on implementing and documenting activities that limit spread from known field sites (e.g. public access points, ponds).

2. Cracking the code of the tuber. All groups identified the need for improved information on hydrilla reproductive propagules (tubers, turions, and seeds) (Netherland 1997). Topics of interest included: 1) susceptibility of tubers and turions to freezing; 2) viability of tubers in dredged material, methods of inactivation, and implications for disposal of dredged material; 3 ) environmental factors that influence sprouting and the timing of tuber sprouting in the North; and 4) exploration of methods to "trigger sprouting." This emphasis on hydrilla tubers likely reflects various management concerns. At the most basic level, the timing of management should coincide with the timing of emergence from tubers and prior to initiation of new tubers. This "window of opportunity" is still not well-defined for northern waters. In addition, the emphasis on freezing and dredged material disposal has significant implications for Corps of Engineer dredging projects if hydrilla becomes established in these areas. Likewise, resource managers recognize that current eradication strategies are based on tuber longevity and an increased understanding of the factors that promote quiescence or sprouting could reduce the time required to achieve eradication. Manipulation of hydrilla tuber sprouting remains somewhat of a "holy grail" of management, yet without further investigation in this area, eradication projects will likely remain long-term endeavors.

3. How invasive is hydrilla likely to be in the North? While current assumptions regarding monoecious hydrilla suggest this plant is likely to be highly invasive in northern waters, the science to describe the invasion ecology including dispersal, establishment, growth, and competition is generally lacking. An increased emphasis on this type of research could be particularly valuable to resource managers as well as those involved in predictive modeling. Predictive models will only be as good as the underlying biological/ecological factors that drive growth and distribution of hydrilla. If hydrilla continues to be introduced into northern 
lakes, reservoirs, rivers, and streams at an increased rate, then managers are eventually going to have to defend their decisions (i.e. eradication, containment, nuisance growth management, or no management). Improved knowledge on what types of systems are at the greatest risk would be particularly valuable for this region. As noted earlier, monoecious hydrilla may be a disturbance specialist and while glacial lakes remain at risk, rivers, reservoirs, and streams could be at equal or greater risk.

4. Can herbicide strategies be improved? The amount of published information on herbicide efficacy versus monoecious hydrilla is very limited (Van et al. 1987, Poovey and Getsinger 2010). While the bleaching herbicide fluridone has been recognized by managers as highly effective on monoecious hydrilla, the requirement for extended exposure periods may not be compatible with certain situations. Likewise, issues related to optimal treatment timing require additional information on tuber sprouting dynamics (e.g. plant phenology information described above would provide useful information on treatment timing). Some of the groups expressed the concern that eradication strategies that rely on 5+ years of largescale herbicide treatments are likely to have negative impacts on native vegetation. The groups emphasized the need to evaluate the effectiveness of additional herbicides on monoecious hydrilla and explore the concept of using contact herbicides for both eradication and containment strategies. The generation of peer-reviewed data on herbicide performance would benefit managers as they determine optimal management strategies following introduction of hydrilla into their systems.

5. Is early detection/rapid response (EDRR) a practical technical objective? All of the groups recognized the value of identifying infestations early and implementing a control strategy. This was tempered by the recognition that current techniques for identifying "new infestations" are likely haphazard at best. Technologies or enhanced survey methods that can increase the ability to detect nascent infestations of hydrilla (as well as other invasive plants) would be of great value to resource managers. The resource managers in the group also spoke of the need to refine and ensure that permit processes allow for an actual rapid response. Several of the managers in the group expressed concern that current regulatory policies are not congruent with EDRR. They stated that if there is to be true EDRR for hydrilla eradication in northern jurisdictions, the process between discovery and management would require significant change.

FURTHER READING AND RESOURCES: For those interested in additional resources, the following websites provide some background information on monoecious hydrilla in the Northeast:

New York Invasive Species Clearinghouse -http://www.nyis.infoStopHydrilla.org

www.northeastans.org

www.weedscience.ncsu.edu/aquaticweeds/hydrilla.PDF

ACKNOWLEDGEMENTS: Thanks are extended to Scott Kishbaugh (New York Department of Environmental Conservation) and Bob Johnson for organizing the special Symposium session on Lake Cayuga. Amy Smagula (New Hampshire Department of Environmental Services) was the official notetaker and her notes accurately captured the content of the presentations as well as the subsequent conversation and discussions that took place during the Symposium. In addition to the official notes, the authors greatly appreciate notes received from several other attendees. Thanks to Lynn Greer (US Army Engineer District, Buffalo) for assisting with site selection and attending to 
details necessary to host a meeting. The Northeast Aquatic Plant Management Society and Aquatic Ecosystem Restoration Foundation supported breaks. Funding for this Symposium was provided by the US Army ERDC Aquatic Plant Control Research Program (APCRP) under the direction of Dr. Linda Nelson (Program Manager) and Dr. Al Cofrancesco (Technical Director).

POINTS OF CONTACT: This technical note was written by Dr. Michael D. Netherland, US Army ERDC, and Mike Greer, US Army Engineer District, Buffalo. For additional information, contact Dr. Netherland (352) 392-0335, Michael.D.Netherland@usace.army.mil or the APCRP Program Manager, Linda S. Nelson (601) 634-2656, Linda.S.Nelson@usace.army.mil. This technical note should be cited as follows:

Netherland, M. D., and M. Greer. 2014. Establishing research and management priorities for monoecious hydrilla. APCRP Technical Notes Collection. ERDC/TN APCRP-MI-8. Vicksburg, MS: US Army Engineer Research and Development Center.

\section{REFERENCES}

Benoit, L.K. 2011. Cryptic speciation, genetic diversity and herbicide resistance in the invasive aquatic plant Hydrilla verticillata (L.f.) Royle (Hydrocharitaceae). PhD diss., University of Connecticut. Paper AAI3492149.

Carter, V., N. B. Rybicki, and C. L. Schulman. 1987. Effect of salinity and temperature on germination of monoecious hydrilla propagules. J. Aquat. Plant Manage. 25:54-57.

Chadwell, T. B., and K. A. Engelhardt. 2008. Effects of pre-existing submersed vegetation and propagule pressure on the invasion success of Hydrilla verticillata. J. Appl. Ecol. 45(2):515-523.

Conant, R. D., T. K. Van, and K. K. Steward. 1984. Monoecious hydrilla produces viable seeds in the United States. Aquatics 6(3):10.

Harlan, S. M., G. J. Davis, and G. J. Pesacreta. 1984. Hydrilla in three North Carolina lakes. J. Aquat. Plant Manage. 23:68-71.

Hofstra, D. E., J. Clayton, J. D. Green, and M. Auger. 1999. Competitive performance of Hydrilla verticillata in New Zealand. Aquat. Bot. 63(3):305-324.

Hofstra, D. E., P. D. Champion, and J. S. Clayton. 2010. Predicting invasive success of Hydrilla verticillata (L.f) Royle in flowing water. Hydrobiologia 656:213-219.

Hoyer, M. V., M. Jackson, M. S. Allen, and D. E. Canfield. 2008. Lack of exotic hydrilla infestation effects on plant, fish, and aquatic bird community measures. Lake Reserv. Manage. 24:331-338.

Langeland, K.A. 1996. Hydrilla verticillata (L.F.) Royle (Hydrocharitaceae), "The Perfect Aquatic Weed." Castanea 61(3):293-304.

Lal, C., and B. Gopal. 1993. Production and germination of seeds in Hydrilla verticillata. Aquat. Bot. 45: 257-261.

Madeira, P. T., T. K. Van, and T. D. Center. 2004. An improved molecular tool for distinguishing monoecious and dioecious hydrilla. J. Aquat. Plant Manage. 42:28-32.

Maki, K. C., and S. M. Galatowitsch. 2008. Cold tolerance of two biotypes of hydrilla and northern watermilfoil. $J$. Aquat. Plant Manage. 46:42-50.

McFarland, D. G., and J. W. Barko. 1987. Effects of temperature and sediment type on growth and morphology of monoecious and dioecious hydrilla. J. Freshw. Ecol. 4(2):245-252.

McFarland, D. G., and J. W. Barko. 1999. High-temperature effects on growth and propagule formation in hydrilla biotypes. J. Aquat. Plant Manage. 37:17-25. 


\section{ERDC/TN APCRP-MI-8}

January 2014

Netherland, M. D. 1997. Turion Ecology of Hydrilla. J. Aquat. Plant Manage. 35:1-10.

Owens, C. S., R. M. Smart, and G. O. Dick. 2012. Tuber and turion dynamics in monoecious and dioecious hydrilla (Hydrilla verticillata), J. Aquat. Plant Manage. 50:58-62.

Poovey, A. G., and K. D. Getsinger. 2010. Comparitive response of monoecious and dioecious hydrilla to endothall. $J$. Aquat. Plant Manage. 48:15-20.

Poovey, A. G., and S. H. Kay. 1998. The potential of a summer drawdown to manage monoecious hydrilla. J. Aquat. Plant Manage. 36:127-130.

Roley, S. S., and R.M. Newman. 2008. Predicting Eurasian watermilfoil invasions in Minnesota. Lake Reserv. Manage. 24(4):361-369.

Ryan, F. J., J. S. Thullen, and D. L. Holmberg. 1991. Non-genetic origin of isoenzymic variability in subterranean turions of monoecious and dioecious hydrilla. J. Aquat. Plant Manage. 29:3-6.

Rybicki, N.B., J.D. Kirshtein, and M.A. Voytek. 2013. Improved insight about the distribution of Hydrilla, Egeria, and Elodea (Hydrocharitaceae): Application of molecular techniques for identification. J. Aquat. Plant Manage.

Spencer, D., L. Anderson, G. Ksander, S. Klaine, and F. Bailey. 1994. Vegetative propagule production and allocation of carbon and nitrogen by monoecious Hydrilla verticillata (L.f.) Royle grown at two photoperiods. Aquat. Bot. 48(2):121-132.

Spencer, D. F., and G. G. Ksander. 2000. Interactions between American pondweed and monoecious hydrilla grown in mixtures. J. Aquat. Plant Manage. 38:5-13.

Spencer, D. F., and G. G. Ksander. 2001. Field evaluation of degree-day based equations for predicting sprouting of hydrilla (Hydrilla verticillata) turions and tubers. J. Freshw. Ecol. 16:479-486.

Spencer, D. F., and L. W. J. Anderson. 1986. Photoperiod responses in monoecious and dioecious Hydrilla verticillata. Weed. Sci. 34(4):551-557.

Steward, K. K. 1991. Competitive interaction between monoecious hydrilla and American eelgrass on sediments of varying fertility. Fla. Sci. 54(3/4):135-147.

Steward, K. K., and T. K. Van. 1987. Comparative studies of monoecious and dioecious hydrilla (Hydrilla verticillata) biotypes. Weed. Science 35:204-210.

Sutton, D. L., T. K. Van, and K. M. Portier. 1992. Growth of dioecious and monoecious hydrilla from single tubers. $J$. Aquat. Plant Manage. 30:15-20.

Van, T. K. 1989. Differential responses to photoperiods in monoecious and dioecious Hydrilla verticillata. Weed. Sci. 37:552-556.

Van, T. K., and K. K. Steward. 1990. Longevity of monoecious hydrilla propagules. J. Aquat. Plant Manage. 28:74-76.

Van, T. K., K. K. Steward, and R. D. Conant, Jr. 1987. Responses of monoecious and dioecious hydrilla (Hydrilla verticillata) to various concentrations and exposures of diquat. Weed. Sci. 35(2):247-52.

Wilde, S. B., T. M. Murphy, C. P. Hope, S. K. Habrun, J. Kempton, A. Birrenkott, F. Wiley, W. W. Bowerman, and A. J. Lewitus. 2005. Avian vacuolar myelinopathy linked to exotic aquatic plants and a novel cyanobacterial species. Environ. Toxicol. 20:348-353.

NOTE: The contents of this technical note are not to be used for advertising, publication or promotional purposes. Citation of trade names does not constitute an official endorsement or approval of the use of such products. 